\title{
EVALUATING FLEXURAL STRENGTH OF RC BEAMS STRENGTHENED BY CFRP USING DIFFERENT ANALYTICAL MODELS
}

\author{
Riyam J. ABED ${ }^{1}$, Mohammed A. MASHREI ${ }^{1, *}$, Ali A. SULTAN ${ }^{1}$ \\ ${ }^{1}$ Civil Engineering Department, University of Thi-Qar, Thi-Qar, Iraq. \\ corresponding author: mamashrei@utq.edu.iq
}

\begin{abstract}
This paper deals with reinforced concrete beams strengthened by CFRP in flexure. The debonding between CFRP and the surface of the beam is the main problem. Many researchers around the world have made extensive efforts to study the phenomenon of debonding for efficient applications. Based on these efforts and different related field applications, code previsions and various models have been proposed for predicting debonding failure. Two code previsions and three typical models are presented in the current study. ACl-440.2R 17, CNR-DT 200 R1/2013, Said and Wu, Lu et al., and Teng et al. have been used to estimate the flexural strength of $R C$ beams strengthened by CFRP with and without grooves. Test results of eleven flexural beams strengthened by CFRP sheet/laminate using externally bonded reinforcement (EBR) and externally bonded reinforcement on grooves (EBROG) methods were used in the current paper. The performance and accuracy of each model were evaluated based on these test results. Most of the prediction models that used in this study give a closer prediction of the flexural strength of beams strengthened by EBR compared to that of the beams strengthened by EBROG. Finally, the prediction results of CNR-DT 200 R1/2013 were the most accurate and approval with test results compared with other models in the current study
\end{abstract}

Keywords:

CFRP;

Strengthening;

Analytical models;

EBROG;

Reinforced concrete beam.

\section{Introduction}

During the past three decades, fiber-reinforced polymer (FRP) has been an increasing interest for using in the strengthening and retrofitting of structural elements. Because of its desired properties such as high tensile strength, low weight, and corrosion resistance [1-3]. Carbon fiber reinforced polymer (CFRP) as externally bonded (EB) is one of the most used techniques to improve the stiffness, strength and structural performance of reinforced concrete $(R C)$ elements. The technique of CFRP external bonding has been confirmed to be an effective and economic solution. Hawileh R. A., et al. [3] conducted an experimental and an analytical study of the flexural behavior of RC beams strengthened with different combinations of fiber reinforced polymer (FRP) using EBR method. The effect of CFRP, GFRP, and hybrid on the load- deflection relationships, strain readings, and failure modes of tested beams have been reported and discussed. Dong J., et al. [4] studied the flexural behavior of RC beams strengthened by external CFRP sheets. The test results showed an increase in the flexural strength of beams strengthened by CFRP sheet ranged by $41-125 \%$.

However, the problem of the debonding CFRP from the surface of the strengthened elements still needs to be overcome in EBR technique. The debonding of CFRP usually occurs before reaching the ultimate capacity of the section. Debonding of the strengthening material may negatively influence its effectiveness and may make such strengthening technique prone to danger due to the high potential of catastrophic failure of the structure.

In order to overcome the problem of CFRP debonding, several attempts have been paid toward exploring alternative strengthening techniques and examining their performance. 
Recently, Mostofinejad and Mahmoudabadi [5] have developed Externally Bonded Reinforcement on Grooves (EBROG) as an alternative to externally bonded reinforcement strengthening method.

Several investigations have been conducted to study the effects of shape, number and direction of grooves on the flexure and shear strengths as well as the failure modes of strengthened members. Among these studies, Hosseini A. and Mostofinejad D. [6] carried out an experimental study to assess the effect of groove dimensions (width and depth) on the bond behavior of strengthened specimens by CFRP using EBR and EBROG methods. The ultimate capacity of specimens strengthened by EBROG was increased up to $27.8 \%$ compared with those strengthened by EBR method. Czaderski C., et al., [7] reported that the using of EBROG method leads to increase the load carrying capacity up to $33 \%$ and change the failure mode from debonding to concrete cover separation. Mostofinejad D., et al. [8] experimentally examined the effect of number of CFRP layers (one, two, and three layers) on strengthened beams using EBROG, Externally Bonded Reinforcement in Grooves (EBRIG) and EBR methods. EBRIG method, CFRP is attached directly to the inner surfaces of the grooves as well as the surfaces outside the grooves on the tensile face of the beam. For one layer of CFRP, the performances of three techniques were found to be approximate. While, the beams strengthened with two layers of CFRP using EBROG and EBRIG methods increased up $25 \%$ compared with one with EBR. For three layers of CFRP using EBROG and EBRIG methods, the increase was $19 \%$ and $24 \%$ respectively. The using of both EBROG and EBRIG methods led to postpone the debonding phenomenon. Sabzi et al. [9] carried out an experimental and analytical study to investigate the behavior of RC beams strengthening by CFRP using EBR and EBROG methods. The results showed that the EBROG method leads to an increase in the ultimate load capacity and ductility of the strengthened elements compared to EBR method. Also, they found that the prediction results of models were in close agreement with test results for beams that were strengthened by EBR method.

A large number of researchers have been proposed models to predict the failure mode and evaluated the existing models of the debonding strength. For example, Lu, X. Z., et al. [10] presented a finite-element (FE) analysis and proposed strength model to investigate the effectiveness and accuracy of theoretical equations to predict the Intermediate crack debonding of beams strengthened by FRP. Both of FE model and simple strength equations are shown to be accurate during comparisons with test results of 42 and 77 beams, respectively. Teng J. G., et al. [11] proposed a model to predict the strength of beams and slabs that fail by Intermediate crack debonding. The proposed model, based on the modification of the bond strength model of Chen and Teng [12] is combined with section analysis. The prediction results of the proposed model is appeared a good agreement with the test results. Kotula P., et al. [13] presented an experimental and numerical study to investigate the anchorage zone of CFRP sheets and lamella using a double tensile test. Kotes, P., et al. [14] the behavior of reinforced concrete beams strengthened by CFRP lamella against bending were studied.

The aim of this study is to assess the accuracy of the theoretical models to predict the flexural strength of RC beams strengthened by CFRP sheet/laminate using EBR and EBROG methods. The performance and accuracy of each model was evaluated based on the experimental results conducted by the authors. The moment capacity equations recommended by the $\mathrm{ACl} 440.2 \mathrm{R}-17$ [15] and other theoretical models were used to verify the margin of safety provided by the discussed code and to verify its accuracy.

\section{Experimental data of existing study}

The experimental program is included eleven reinforced concrete beams, all beams were $120 \mathrm{~mm} \cdot 150 \mathrm{~mm}$ in cross-section and $1300 \mathrm{~mm}$ in length. Fig. 1 shows the details of beam specimens. 

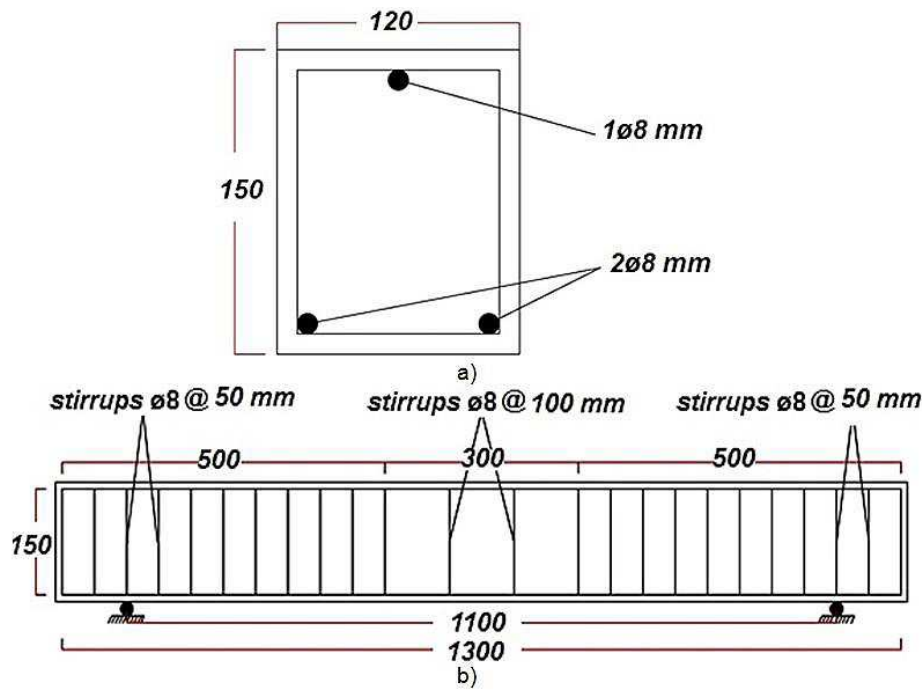

Fig. 1: Details of beam specimens: a) cross section; b) longitudinal section.

Two types of CFRP were used in the current study. The first type is CFRP sheet with $100 \mathrm{~mm}$ in width and the second type is CFRP laminate with $50 \mathrm{~mm}$ or $100 \mathrm{~mm}$ in width. The properties as per the manufacturer are presented in Table 1. The details of flexural strengthening for beams are presented in Table 2. Both types of CFRP are applied to the tension face of the beam surface with a length equal to $1000 \mathrm{~mm}$. All other materials used in the experimental work such as cement, aggregate and steel have been tested according the ASTM Standards.

Table 1: Properties of CFRP.

\begin{tabular}{|c|c|c|c|}
\hline Material & Property & CFRP-Sheet & CFRP-Laminate \\
\hline \multirow{4}{*}{ CFRP } & Tensile strength [MPa] & 4300 & 2800 \\
\cline { 2 - 4 } & Tensile modulus [GPa] & 238 & 165 \\
\cline { 2 - 4 } & Thickness [mm] & 0.131 & 1.2 \\
\cline { 2 - 4 } & Elongation at break [\%] & 1.8 & 1.69 \\
\hline
\end{tabular}

Table 2: Details of flexural strengthening of beam specimens.

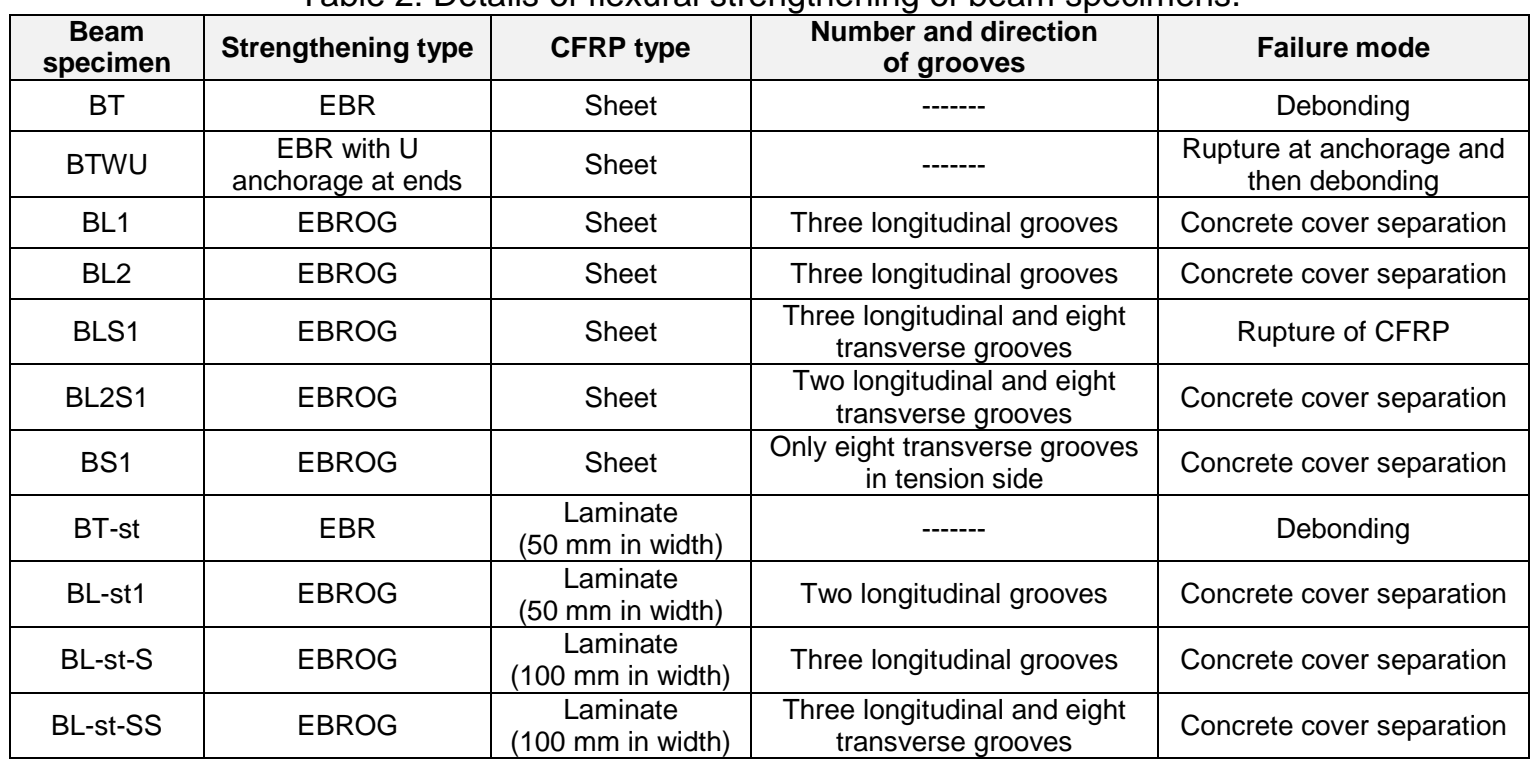

In this study, two types of grooves longitudinal and transverse have been employed. All longitudinal grooves were cut in length $1000 \mathrm{~mm}$, width $10 \mathrm{~mm}$ and depth $7 \mathrm{~mm}$ using grinder machine. While, transverse grooves was cut in length $100 \mathrm{~mm}$, width $10 \mathrm{~mm}$ and depth $7 \mathrm{~mm}$. Fig. 2 shows the longitudinal and transverse grooves. 


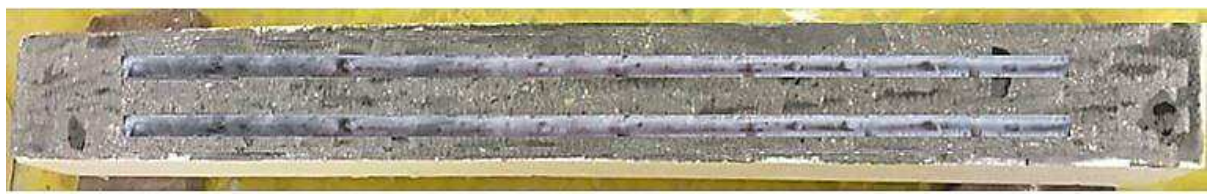

a) The beam with two longitudinal grooves

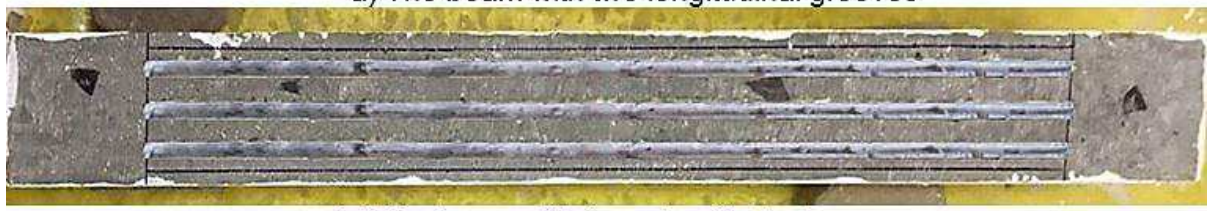

b) The beam with three longitudinal grooves

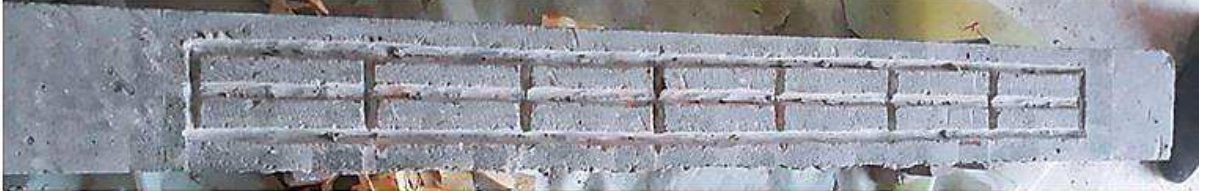

c) The beam with three longitudinal grooves and eghit transverse grooves

Fig. 2: Details of longitudinal and transverse grooves.

Based on the experimental results of existing study, three typical failure patterns of strengthened beams, which observed during the test is presented in Fig. 3. These three failure patterns are termed: a) debonding of CFRP, b) concrete cover separation, and c) CFRP rupture.

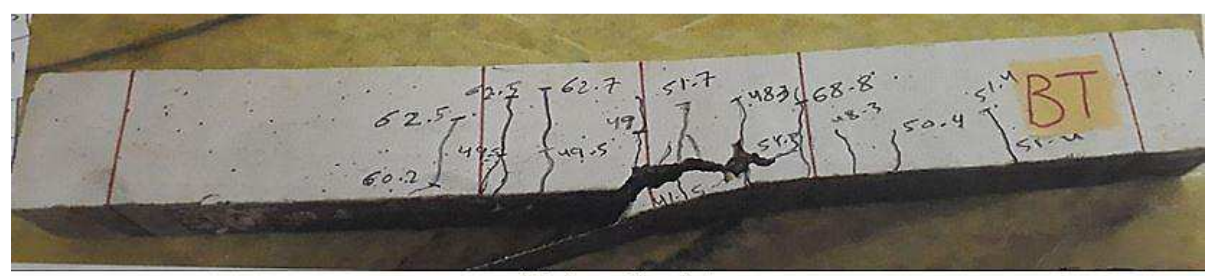

a) Debonding failure

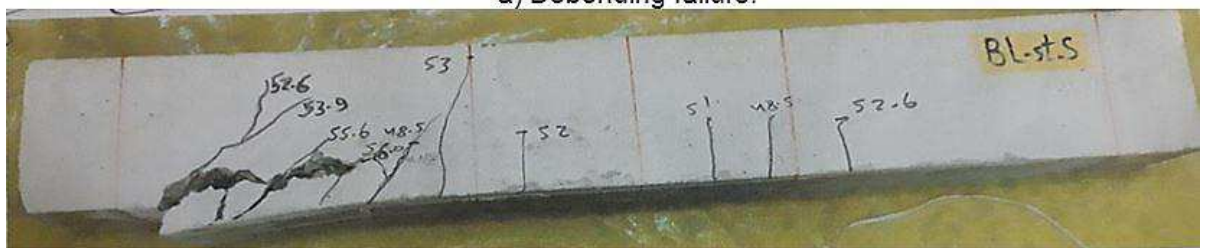

b) Concrete cover separation failure

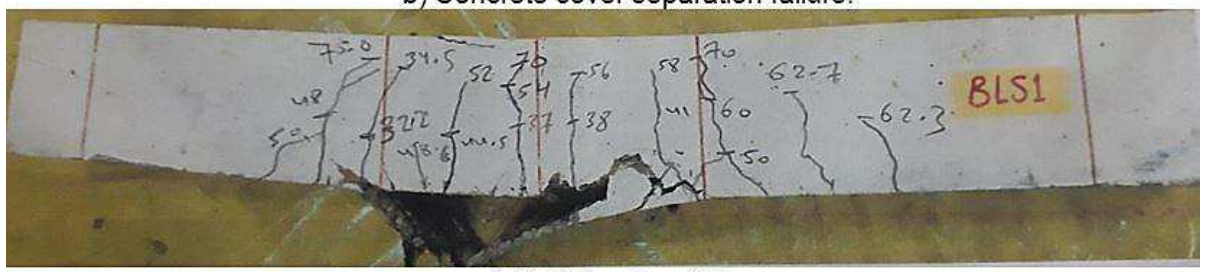

c) CFRP rupture failure.

Fig. 3: Failure modes of existing study.

The test of existing study has shown that the ultimate capacity of RC beams strengthened by CFRP in flexural is often limited by concrete cover separation. This failure is occurred due to high interfacial stresses nigh the ends of CFRP and then detachment of the CFRP together with a concrete cover.

\section{Appraisal of the existing models to predict the flexural strength}

\subsection{ACl-440.2R 17}

In this section, the approach employed by the $A C I 440.2 R$ [15] is intended to analyze RC beams strengthened by means of EBR or by NSM FRP reinforcement. In this research, however, the moment capacity of all tested beams has been calculated according to the code equations. Even though some of them are not explicitly among any of the categories above, presence of grooves may make the 
strengthened beams be classified in somewhat between EBR beams and NSM beams. Because of FRP materials are linear elastic until failure, the design elasticity modulus for unidirectional FRP can be found by using Hooke's low. The expression of elasticity modulus is given in Eq. (1).

$E_{f}=f_{f u} / \varepsilon_{f u}$,

where $E_{f}$ is the elasticity modulus of FRP, $f_{f u}$ is the ultimate tensile strength of the FRP, and $\varepsilon_{f u}$ is the ultimate rupture strain of FRP reinforcement.

The design approach of flexural strength includes that the design flexural strength of element $\varnothing M_{n}$ exceed its required factored moment $M_{u}$, as defined in Eq. (2).

$\emptyset M_{n} \geq M_{u}$.

This section is intended to verify the accuracy of the analysis and design approach of the $\mathrm{ACl}$ 440.2R-17 and to determine the margin of safety provided by the proposed equations. Fig. 4 explains the strain and stress distribution for a rectangular section under flexure at the ultimate limit state. For each individual beam, the nominal moment capacity has been calculated according to the following equations:

$M_{n}=A_{s} f_{s}\left(d-\frac{\beta_{1} c}{2}\right)+\psi_{f} A_{f} f_{f d}\left(d_{f}-\frac{\beta_{1} c}{2}\right)$,

where $M_{n}$ is the bending moment (nominal), $A_{s}$ and $A_{f}$ are the areas (cross-sectional) of tensile reinforcement, and FRP sheet/laminate, respectively. $f_{s}$ is the yield strength in steel reinforcement, and $f_{f d}$ is the design strength of externally bonded FRP reinforcement and can be computed by Eq. (4). $c$ is the neutral axis depth, $d$ and $d_{f}$ are the effective depth of tensile steel reinforcement and FRP reinforcement. $\psi_{f}$ is the factor of reduction created by FRP, which is equal to 0.85 , this reduction factor is based on the reliability analysis that was dependent on the experimentally measured statistical characteristics of the flexural strength. $\beta_{1}$ is the ratio of depth of equivalent rectangular stress block to the depth of the natural axis. If the controlling failure mode is concrete crushing (after or before yielding of steel reinforcement) $\beta_{1}$ can be taken equivalent to 0.85 for concrete strength $f_{c}^{\prime}$ between 17 $\mathrm{MPa}$ and $27 \mathrm{MPa}$. While, if the $f_{c}^{\prime}$ exceeding $27 \mathrm{MPa}, \beta_{1}$ should be reduced at rate of 0.05 for each 7 $\mathrm{MPa}$ of concrete strength increasing. However, $\beta_{1}$ shall not be taken less than 0.65 . If the controlling failure mode is cover delamination, FRP rupture or FRP debonding, the Whitney stress block will give rationally accurate results. $f_{f e}$ can be obtained from equation (5) below

$f_{f d}=E_{f} \varepsilon_{f d}$,

$f_{f e}=E_{f} \varepsilon_{f e}$,

where $f_{f e}$ is effective stress of the FRP (stress obtained at section failure) and $\varepsilon_{f e}$ is the effective strain in the FRP reinforcement, as defined in equation (6)

$$
\varepsilon_{f e}=\varepsilon_{c u}\left(\frac{d_{f}-c}{c}\right)-\varepsilon_{b i} \leq \varepsilon_{f d},
$$

$\varepsilon_{c u}$ is the ultimate usable strain in concrete (i.e. 0.003 ), $\varepsilon_{b i}$ is the initial stain on the bonded substrate, it can found based on the elastic analysis of the existing element (all loads will be applied on the element during FRP installation). $\varepsilon_{f d}$ is the upper limit of the FRP strain at which the debonding failure may occur and can be calculated from equation (7) below

$\varepsilon_{f d}=0.41 \sqrt{\frac{f_{c}^{\prime}}{n E_{f} t_{f}}} \leq 0.9 \varepsilon_{f u}$,

where $f_{c}^{\prime}$ is the compressive strength of concrete, $t_{f}$ is the thickness of FRP, $n$ is the number of FRP layers and $\varepsilon_{f u}$ is the rupture strain of FRP. The Eq. (7) takes a modified formula of the equation of debonding stain proposed by Teng et al. [11, 16]. To find the best-appropriate coefficient of $(0.41$ in $\mathrm{SI}$ ) for the proposed equation by Teng, it was calibrated by using average measured values of strains of FRP debonding. 


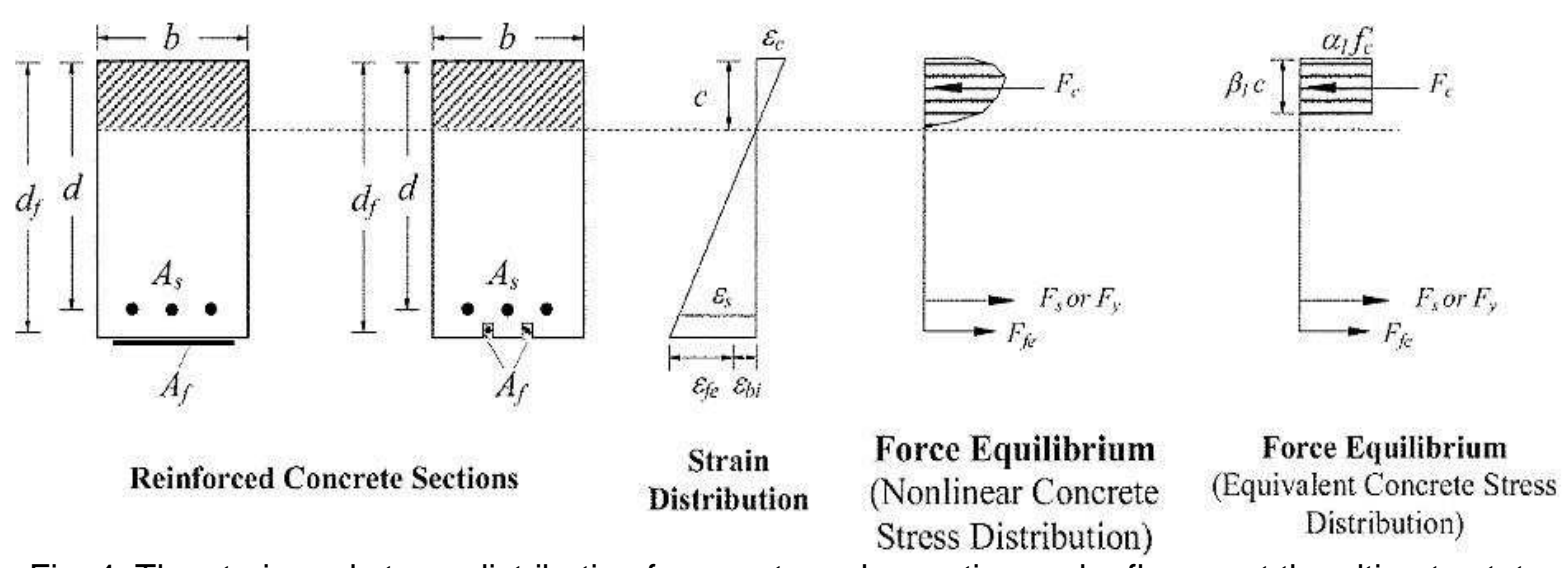

Fig. 4: The strain and stress distribution for a rectangular section under flexure at the ultimate state.

\subsection{CNR-DT 200 R1 / 2013}

The Italian code CNR-DT 200 R1 / 2013 [17] presents an accurate criterion for design and analysis of members strengthened by FRP using EBR method at the ultimate limit state (ULS). Base on this code, the maximum tensile strain of FRP is calculated by Eq. (8)

$\varepsilon_{f d}=\min \left\{\eta_{a} \frac{\varepsilon_{f k}}{\gamma_{f}}, \varepsilon_{f d d}\right\}$,

where $\varepsilon_{f k}$ is the FRP characteristic strain at failure (rupture) and can be expressed by Eq. (9), $\eta_{\alpha}$ is an environmental coefficient (in this study, equal to 0.95), $y_{f}$ is FRP material partial factor (in this study, equal to 1.0). $\varepsilon_{\text {fdd }}$ is FRP strain at debonding and can be given in Eq. (10).

$\varepsilon_{f k}=f_{f k} / E_{f}$,

$\varepsilon_{f d d}=\frac{k_{q}}{\gamma_{f, d}} \sqrt{\frac{2 \cdot k_{b} \cdot k_{G, 2}}{n \cdot E_{f} \cdot t_{f} \cdot F_{C}} \sqrt{f_{c m} \cdot f_{c t m}}}$,

where $f_{f k}$ is the ultimate tensile strength (provided by manufactory), $k_{\alpha}$ is a factor that depend on load distributions $\left(k_{\alpha}=1\right.$ for concentrated load and $k_{\alpha}=1.25$ for distributed load), $y_{f d}$ is a safety coefficient equal to 1.0. $F_{c}$ is the confidence factor equal to $1.0, f_{c m}$ and $f_{c t m}$ are the concrete compressive and tensile strengths, respectively $f_{c t m}$ can be expressed by Eq. (11). $k_{G, 2}$ is a corrective coefficient calibrated from test results and equal to 0.32 and $0.10 \mathrm{~mm}$, respectively (irrespective of the type of reinforcement), $k_{b}$ is the geometrical corrective factor and can be calculated from the Eq. (12):

$f_{c t m}=0.1 f_{c m}$

$k_{b}=\sqrt{\frac{2-b_{f} / b}{1+b_{f} / b}} \geq 1$ for $b_{f} / b \geq 0.25$,

where, if $b_{f} / b<0.25, k_{b}=1.18, b_{f}$ and $b$ are the width of FRP and beam section respectively. The maximum tensile strength of FRP reinforcement $f_{f d}$ can be calculated by Eq. (13)

$f_{f d}=f_{d e b}=E_{f} \cdot \varepsilon_{f d}$.

Based on the following equation can be calculated the maximum tensile moment $M_{\text {deb }}$ of FRP reinforcement

$f_{d e b}=\frac{M_{d e b^{\cdot} c}}{I}$,

where $I$ is the moment of inertia of the section. 


\subsection{Said and Wu model}

Said and $\mathrm{Wu}$ [18] suggested a simple model to predict the ultimate capacity of CFRP strengthened sections in flexural due to debonding failure. After, the CFRP debonding occurs and the FRP strain at debonding $\varepsilon_{d e b}$ may be expressed in a general form by the following equation

$\varepsilon_{d e b}=C 1\left(f^{\prime}{ }_{c}\right)^{C 2} /\left(E_{f} t_{f}\right)^{C 3}$,

where $C 1, C 2$ and $C 3$ are constants that may be computed base on the available experimental results. By assuming the value of $C 2$, the two other constant $C 1$ and $C 3$ can be calibrated to get the most accurate predictions. The required level of accuracy was occurred by the lowest level of dispersion and the smallest range of predicted to experimental load ratios. The critical value of FRP strain at debonding $\varepsilon_{d e b}$ can be calculated by the following equation

$\varepsilon_{\text {deb }}=0.23\left(f^{\prime}{ }_{c}\right)^{0.2} /\left(n E_{f} t_{f}\right)^{0.35}$.

Based on Eq. (16) and considering that after steel yielding, IC debonding usually occurs, the moment capacity of FRP strengthened members in flexural at debonding can be expressed as follows

$M_{d e b}=A_{s} f_{y} y_{c t}+0.23 b_{f}\left(f^{\prime}\right)^{0.2}\left(n E_{f} t_{f}\right)^{0.65}\left(y_{c t}+c^{*}\right)$,

where $M_{d e b}$ is the bending moment (at debonding), $f_{y}$ is the yield stress in steel reinforcement, $y_{c t}$ is the distance between the tensile force of steel reinforcement and the compressive force of the compression part of the section. $b_{f}$ is the width of CFRP, $c^{*}$ is the distance between the centroid of the tensile steel and the centroid of the FRP. The value of $y_{c t}$ may be carefully computed by applying the equations of strain compatibility and static equilibrium of the section. For quick calculations, rectangular cross sections $y_{c t}$ may be considered equivalent to the effective depth $d$ multiplied by 0.9 . So that, Eq. (17) may be rewritten as follows

$M_{d e b}=0.9 A_{s} f_{y} d+0.23 b_{f}\left(f^{\prime}{ }_{c}\right)^{0.2}\left(n E_{f} t_{f}\right)^{0.65}\left(0.9 d+c^{*}\right)$.

For design purposes, a suitable safety factor should be presented. Based on the available experimental results, a reduction factor of strength of 0.75 is recommended. So, Eq. (17) may be modified as follows

$M_{\text {deb, des }}=0.75\left\{0.9 A_{s} f_{y} d+0.23 b_{f}\left(f^{\prime}{ }_{c}\right)^{0.2}\left(n E_{f} t_{f}\right)^{0.65}\left(0.9 d+c^{*}\right)\right.$.

\subsection{Lu et al. model}

Lu et al. [10] proposed a model to predict the debonding failure of members strengthened by CFRP in flexural. Based on the stress blocks, the total axial force in the FRP plate at the loaded section is expressed by

$T=\left(\frac{\tau_{c, \max } L_{e e}}{2}+\frac{\tau_{s, \max } L_{d}}{2}\right) b_{f}$,

where $T$ is the total axial force of FRP, $L_{e e}$ is the effective bond length corresponding to bond-slip model for the major flexural crack zone, which can be calculated by the Eq. (21). $L_{d}$ is the distance from the loaded section to the end of the FRP plate. $T_{c, \max }$ is the maximum value of the crack-induced interfacial shear stress, $T_{c, \text { max }}$ is the maximum value of the shear force-induced interfacial shear stress, which can be expressed by the equations (22) and (23)

$$
\begin{aligned}
& L_{e e}=0.228 \sqrt{E_{f} t_{f}}, \\
& \tau_{s, \max }=\alpha \tau_{\text {max }}, \\
& \tau_{c, \text { max }}=(1-\alpha) \tau_{\text {max }}, \\
& \alpha=3.41 L_{e e} / L_{d},
\end{aligned}
$$


where

$\tau_{\max }=1.5 \beta_{w} f_{t}$,

$\beta_{w}=\sqrt{\left(2.25-\left(\frac{b_{f}}{b}\right)\right) /\left(1.25+\left(\frac{b_{f}}{b}\right)\right)}$,

$f_{t}=0.53 \sqrt{f_{c}^{\prime}}$,

$f_{t}$ denotes to the tensile concrete strength, $b$ and $b_{f}$ are the width of beam and FRP, respectively. According to this model, the debonding strain of FRP $\varepsilon_{f}^{I C}$ can be defined by Eq. (28) below

$\varepsilon_{f}^{I C}=\frac{0.114(4.41-\alpha) \tau_{\max }}{\sqrt{n E_{f} t_{f}}}$.

The maximum tensile strength of FRP reinforcement, $f_{f}$ can be calculated by Eq. (29)

$f_{f}=f_{d e b}=E_{f} \cdot \varepsilon_{f}^{I C}$.

Based on the following equation can be calculated the maximum tensile moment $M_{\text {deb }}$ of FRP reinforcement

$f_{\text {deb }}=\frac{M_{d e b \cdot c}}{I}$,

where $I$ is the moment of inertia of the section.

\subsection{Teng et al. model}

Teng et al. [11] proposed a model, based on the effect of concrete compressive strength, axial stiffness of FRP, $n E_{f} t_{f}$ and width ratio $b_{f} / b$ on the debonding failure. In this model, the debonding strain can be expressed by the following equations

$\varepsilon_{d e b}=\left\{\begin{array}{ll}0.48 \beta_{w} \sqrt{\frac{\sqrt{f^{\prime} E_{c}}}{n E_{f} t_{f}}} & \text { If } L_{f} \geq \sqrt{\frac{n E_{f} t_{f}}{\sqrt{f^{\prime} \prime_{c}}}} \\ 0.48 \sin \left\{\frac{\pi L_{f}}{\left.2 \sqrt{\frac{n E_{f} t_{f}}{\sqrt{f^{\prime} c_{c}}}}\right\} \beta_{w} \sqrt{\frac{n E_{f} t_{f}}{\sqrt{f^{\prime} c}}}}\right. & \text { If } L_{f}<\sqrt{\frac{n E_{f} t_{f}}{\sqrt{f^{\prime} c_{c}}}}\end{array}\right.$,

$\beta_{w}=\sqrt{\left(2-b_{f} / b\right) /\left(1+b_{f} / b\right)}$,

where $L_{f}$ is the distance from the FRP cutoff to the nearest applied load and $\beta_{w}$ is the width ratio factor. Based on this model, the ultimate stress for IC debonding $\sigma_{d b i c}$ can be calculated by Eq. (33) below

$\sigma_{d b i c}=0.48 \beta_{P} \beta_{L} \sqrt{\frac{E_{f} \sqrt{f^{\prime} c}}{t_{f}}}$,

where $\beta_{p}$ and $\beta_{L}$ can be expressed by the following equations

$\beta_{P}=\sqrt{\frac{2-b_{f} / b}{1+b_{f} / b}}$, 
$\beta_{L}=\left\{\begin{array}{lll}1 & \text { if } & L_{f} \geq L_{e} \\ \sin \frac{\pi L_{f}}{2 L_{e}} & \text { if } & L_{f}<L_{e}\end{array}\right.$,

in which $L_{e}$ is the effective bond length and can be defined as follows

$L_{e}=\sqrt{\frac{E_{f} t_{f}}{\sqrt{f^{\prime} c}}}$.

Based on the following equation can be calculated the maximum tensile moment $M_{d e b}$ of FRP reinforcement

$\sigma_{d b i c}=\frac{M_{d e b^{\cdot} c}}{I}$.

\section{Comparison of test results with existing models}

This section carried out an inclusive comparison among the experimental results $P_{\text {Exp }}$ conducted by authors and flexural strength models $P_{P r e}$ in order to check the accuracy and validity of ACl-440.2R 17, CNR-DT 200 R1 / 2013, Said and Wu model, Lu et al. model, and Teng et al. model in estimate flexural strength of RC beams strengthened by CFRP sheet or laminate in presence of grooves. Table 3 summarizes the ratio between prediction load by equations and experimental load $P_{\text {Pre }} I P_{\text {Exp }}$ of all tested beams. The prediction results that obtained from $\mathrm{ACl}$ and Said and $\mathrm{Wu}$ models were underestimated results for beams strengthened by CFRP sheet and overestimated for RC beams strengthened by CFRP laminate. The prediction results that obtained based on the models of Teng et al., and Lu et al. have underestimated results for RC beams strengthened by CFRP sheet / laminate and more agreement with those of experimental results compared with $\mathrm{ACl}$ and Said models. While, the prediction results of CNR-DT 200 R1/2013 were the most accurate and in agreement with test results compared with other models in current study. From Table 3 can be noted that most of the analytical models used in this study give a closer prediction of the flexural strength of beams strengthened by EBR compared to that of the beams strengthened by EBROG. This may be due to the effect of grooves in EBROG is not taken into consideration in calculations of models.

Table 2: Comparison of results from test and flexural strength models.

\begin{tabular}{|c|c|c|c|c|c|c|c|c|c|c|c|c|}
\hline \multirow{2}{*}{ No. } & \multirow{2}{*}{ Beam } & \multirow{2}{*}{$\begin{array}{c}\boldsymbol{f}_{c}^{\prime} \\
{\left[\mathrm{N} / \mathrm{mm}^{2}\right]}\end{array}$} & \multirow{2}{*}{$n$} & \multirow{2}{*}{$\begin{array}{c}E_{f} \\
{\left[\mathrm{~N} / \mathrm{mm}^{2}\right]}\end{array}$} & \multirow{2}{*}{$\underset{[\mathrm{mm}]}{t_{f}}$} & \multirow{2}{*}{$\begin{array}{c}b_{f} \\
{[\mathrm{~mm}]}\end{array}$} & \multirow{2}{*}{$\begin{array}{l}P_{E x p} \\
{[\mathrm{kN}]}\end{array}$} & \multicolumn{5}{|c|}{$\boldsymbol{P}_{\text {Prel }} \boldsymbol{P}_{\text {Exp }}$} \\
\hline & & & & & & & & $\mathrm{ACl}-440$ & CNR-DT & Said and Wu & Lu et al. & Teng et al \\
\hline 1 & BT & 30.64 & 1 & 238000 & 0.131 & 100 & 63.0 & 0.91 & 1.03 & 0.92 & 0.93 & 0.84 \\
\hline 2 & BTWU & 30.17 & 1 & 238000 & 0.131 & 100 & 64.5 & 0.88 & 1.01 & 0.90 & 0.91 & 0.82 \\
\hline 3 & BL1 & 31.08 & 1 & 238000 & 0.131 & 100 & 70.33 & 0.82 & 0.93 & 0.83 & 0.84 & 0.76 \\
\hline 4 & BL2 & 31.08 & 2 & 238000 & 0.131 & 100 & 73.5 & 0.67 & 0.81 & 1.02 & 0.75 & 0.70 \\
\hline 5 & BLS1 & 30.64 & 1 & 238000 & 0.131 & 100 & 75.1 & 0.76 & 0.87 & 0.78 & 0.78 & 0.71 \\
\hline 6 & BL2S1 & 30.63 & 1 & 238000 & 0.131 & 100 & 70.6 & 0.81 & 0.92 & 0.82 & 0.83 & 0.75 \\
\hline 7 & BS1 & 30.63 & 1 & 238000 & 0.131 & 100 & 63.65 & 0.90 & 1.02 & 0.92 & 0.92 & 0.83 \\
\hline 8 & BT-st & 30.17 & 1 & 160000 & 1.2 & 50 & 53.04 & 1.20 & 0.97 & 1.44 & 0.94 & 0.92 \\
\hline 9 & BL-st1 & 29.28 & 1 & 160000 & 1.2 & 50 & 56.0 & 1.13 & 0.92 & 1.36 & 0.89 & 0.87 \\
\hline 10 & BL-st-S & 29.28 & 1 & 160000 & 1.2 & 100 & 56.1 & 1.70 & 0.91 & 2.20 & 0.87 & 0.86 \\
\hline 11 & BL-st-SS & 29.28 & 1 & 160000 & 1.2 & 100 & 58.5 & 1.63 & 0.88 & 2.11 & 0.84 & 0.82 \\
\hline
\end{tabular}

\section{Conclusions}

In this study, analytical results were presented in order to evaluate the effectiveness and accuracy of the equations used to analysis of RC beams strengthened with CFRP sheets/laminates using the groove method. The moment capacity equations recommended by the $\mathrm{ACl} 440.2 \mathrm{R}-17$ and other theoretical models were used to verify the margin of safety provided by the discussed code and to verify its accuracy. Based on the results of prediction models, the following conclusions can be noted: 
1) The results obtained from $\mathrm{ACl}$ and Said and Wu models were underestimated results for beams strengthened by CFRP sheet and overestimated for RC beams strengthened by CFRP laminate.

2) The results that obtained from the models of Teng et al. and Lu et al. have underestimated results for RC beams strengthened by CFRP sheet / laminate and more agreement with those of test results compared with $\mathrm{ACl}$ and Said models.

3) CNR-DT $200 \mathrm{R} 1 / 2013$ results were the most accurate and in agreement with test results compared with other models in current study.

4) Most of the analytical models used in this study give a closer prediction of the flexural strength of beams strengthened by EBR compared to that of the beams strengthened by EBROG.

\section{References}

[1] RAJCHEL, M. - SIWOWSKI T.: Hybrid Bridge Structures made of FRP Composite and Concrete. Civil and Environmental Engineering Reports, Vol. 26, Iss. 3, 2017, pp. 161-169.

[2] KIM, S.: Ductility of Carbon Fiber-Reinforced Polymer (CFRP) Strengthened Reinforced Concrete Beams. Civil and Environmental Engineering-Dissertations, Doctor of Philosophy (PhD), 2003.

[3] BENIN, A. - BOGDANOVA, E.: Influence of Storage Conditions and Corrosive Environments on the Mechanical Properties of GFRP Rebars. Civil and Environmental Engineering, Vol. 14, Iss. 2, 2018, pp. 86-90.

[4] HAWILEH, R. A. et al.: Behavior of reinforced concrete beams strengthened with externally bonded hybrid fiber reinforced polymer systems. Materials \& Design, Vol. 53, 2014, pp. 972-982.

[5] DONG, J. et al.: CFRP sheets for Flexural Strengthening of RC Beams. International Conference on Multimedia Technology (IEEE), 2011, pp. 1000-1003.

[6] MOSTOFINEJAD, D. - MAHMOUDABADI, E.: Grooving as Alternative Method of Surface Preparation to Postpone Debonding of FRP Debonding of FRP Laminates in Concrete Beams. Journal of Composite For Construction, Vol 14, Iss. 6, 2010, pp. 804-811.

[7] HOSSEINI, A. - MOSTOFINEJAD, D.: Effect of Groove Characteristics on CFRP-to-Concrete Bond Behavior of EBROG Joints: Experimental Study Using Particle Image Velocimetry (PIV). Construction and Building Materials, Vol. 49, 2013, pp. 364-373.

[8] CZADERSKI, C. et al.: EBROG Technique to Enhance the Bond Performance of CFRP strips to Concrete Substrate. SMAR 2019-Fifth Conference on Smart Monitoring, Assessment and Rehabilitation of Civil Structures, 2019.

[9] MOSTOFINEJAD, D. - SHAMILI S. M. N. - HOSSEINI A.: EBROG and EBRIG methods for strengthening of RC beams by FRP sheets. European Journal of Environmental and Civil Engineering, Vol. 18, Iss. 6, 2014, pp. 652-668.

[10] SABZI, J. et al.: Effect of Concrete Strength and Longitudinal Reinforcement Arrangement on the Performance of Reinforced Concrete Beams Strengthened Using EBR and EBROG Methods. Engineering Structures, Vol. 205, 2020, pp. 110072.

[11] LU, X. Z. - TENG, J. G. - YE, L. P. - JIANG, J. J.: Intermediate crack debonding in FRPstrengthened RC beams: FE analysis and strength model. Journal of Composites for Construction, Vol. 11, Iss. 2, 2007, pp. 161-174.

[12] TENG, J. G. - SMITH, S. T. - YAO, J. - CHEN, J. F.: Intermediate crack-induced debonding in RC beams and slabs. Constr. Build. Mater., Vol. 17, Iss. 6, 2003, pp. 447-462.

[13] CHEN J. F. - TENG J. G.: Anchorage strength for FRP and steel plates bonded to concrete. J. Struct Eng ASCE, Vol. 127, Iss. 1, 2001, pp. 784-791.

[14] KOTULA, P. - KOTES, P. - BRODNAN, M.: Experimental and Numerical Analysis of Anchorage Zone of CFRP Sheet, Concrete and Concrete Structures, 2013 - 6th International Conference, Slovakia, Procedia Engineering, Vol. 65, 2013, pp. 176-185.

[15] KOTES, P. - FARBAK, M. - KOTULA, P. et al.: Using CFRP Lamellas for Strengthening of Dynamically Loaded Beams, Concrete and Concrete Structures, 2013 - 6th International Conference, Slovakia, Procedia Engineering, Vol. 65, 2013, pp. 302-310.

[16] ACl 440.2R-17: Guide for the design and construction of externally bonded FRP systems for strengthening concrete structures. Reported by ACI Committee 440, 2017.

[17] TENG, J. G. et al.: Recent Research on Intermediate Crack Induced Debonding in FRP Strengthened Beams. Proceedings of the 4th International Conference on Advanced Composite Materials for Bridges and Structures, Calgary, AB, Canada, 2004.

[18] CNR-DT 200 R1/2013: Guide for the design and construction of externally bonded FRP systems for strengthening existing structures. National Research Council, Roma, Italy, 2013. 
[19] SAID, H. - WU, Z.: Evaluating and proposing models of predicting IC debonding failure. J Compos. Constr., Vol. 12, Iss. 3, 2008, pp. 284-299. 